Tropical Journal of Pharmaceutical Research March 2017; 16 (3): 665-672

ISSN: $1596-5996$ (print); 1596-9827 (electronic)

(C) Pharmacotherapy Group, Faculty of Pharmacy, University of Benin, Benin City, 300001 Nigeria.

All rights reserved.

Available online at http://www.tjpr.org

Original Research Article

http://dx.doi.org/10.4314/tjpr.v16i3.23

\title{
Prognostic implications of plasma fibrinogen and serum C- reactive protein levels in non-small cell lung cancer resection and survival
}

\author{
Lian-Yong Jiang ${ }^{1}$, Xue-Feng Zhang ${ }^{2}$, Fang-Bao Ding ${ }^{1 *}$, Ming-Song Wang ${ }^{1}$, Ju \\ $\mathrm{Mei}^{1}$ and $\mathrm{Yi} \mathrm{He}^{1}$ \\ ${ }_{1}^{1}$ Department of Cardiothoracic Surgery, Xinhua Hospital, Shanghai Jiaotong University of Medicine College, Shanghai 200092, \\ ${ }^{2}$ Department of Radiology, Changhai Hospital, Affiliated to the Second Military Medical University, Shanghai 200433, China \\ ${ }^{\star}$ For correspondence: Email: dingfang98@gmail.com
}

\begin{abstract}
Purpose: To investigate the prognostic implications of plasma fibrinogen and serum C-reactive protein (CRP) levels in tumour resection and survival following successful tumour resection in patients with nonsmall cell lung cancer (NSCLC).

Methods: One hundred and fifty-three NSCLC patients who underwent surgical resection at a tertiary care hospital from January 2006 through December 2010 were enrolled. Pre-operative serum CRP and plasma fibrinogen levels were measured. The levels of these biomarkers correlated with tumour size and pathologic TNM stage. The possibility of complete resection and associated findings are reported.

Results: Plasma fibrinogen $(r=0.381, p=0.002)$ and serum $C R P(r=0.471, p<0.001)$ levels were positively associated with tumour diameter. Increased levels of these biomarkers were significantly associated with sex, smoking status, histological type, tumour stage, and clinical stage. Partial tumour resection occurred in $28 \%$ (27/95) of patients with an increased plasma fibrinogen level compared to 10 $\%(6 / 58)$ with a normal fibrinogen level $(p=0.008)$, and in $30 \%(29 / 97)$ of patients with an increased serum CRP level compared to $11 \%(6 / 56)$ with a normal CRP level $(p=0.006)$. Patients with elevated CRP and fibrinogen concentrations demonstrated higher susceptibility to disease advancement and survival compared to patients with normal fibrinogen and CRP levels.

Conclusion: Pre-operative functional concentrations of serum CRP and plasma fibrinogen could serve as indicators of tumour resectability wherein a high tumour resection rate is possible in patients with favourable pre-operative levels of these biomarkers. Increased concentrations of serum CRP and plasma fibrinogen are associated with poor overall survival and progression-free survival.
\end{abstract}

Key words: Plasma fibrinogen, serum C-reactive protein, biomarker, non-small cell lung cancer

Tropical Journal of Pharmaceutical Research is indexed by Science Citation Index (SciSearch), Scopus, International Pharmaceutical Abstract, Chemical Abstracts, Embase, Index Copernicus, EBSCO, African Index Medicus, JournalSeek, Journal Citation Reports/Science Edition, Directory of Open Access Journals (DOAJ), African Journal Online, Bioline International, Open-J-Gate and Pharmacy Abstracts

\section{INTRODUCTION}

Lung cancer is the most frequently observed human malignancy worldwide [1]. The World Health Organisation (WHO) reported that lung cancer causes more than 1.6 million deaths annually; moreover, the stated overall 5-year survival rate following diagnosis is approximately
$15 \%$ [1]. Non-small cell lung cancer (NSCLC) represents more than $85 \%$ of all lung cancers [1]. Tumour resection has been the standard treatment for many years; however, more than $60 \%$ of NSCLC patients have metastatic or advanced tumours at initial presentation [2], which precludes surgical resection. A difficult-tooperate malignant lung tumour with limited 
metastasis detected before surgery can be made operable using pre-operative chemotherapy and/or radiotherapy [3]. However, in patients with inoperable tumours with widespread metastasis, palliative care may be given without surgery. Although several imaging modalities such as chest X-rays, computerised tomography (CT) scanning, and magnetic resonance imaging (MRI) can be used to evaluate lung tumours and operability, the specificity and sensitivity of these techniques differ amongst tumour types [4,5]. The costs associated with such procedures are also high. There is urgent need for a preoperative biochemical screening test that will aid in determining the operability of NSCLC.

The concept of inflammation in cancer pathogenesis is well established [6]. Serum Creactive protein (CRP), a common and shortterm reactive substance produced by the liver, is elevated in a number of chronic inflammatory illnesses, including cancer [6]. Possible mechanisms of elevated serum CRP levels in cancer may be due to tumour growth, the immune response to the tumour, and increased inflammatory cytokine production by tumour cells [7]. Serum CRP is elevated in several tumours, including lung cancers, and its relationship with prognosis has been evaluated in advanced NSCLC [8] and in resectable disease [9]. However, there are several disagreements in the few studies that have evaluated the relationships between CRP level, tumour size, and survival in patients with NSCLC [10]. There may also be a relationship between coagulation and malignancy. Hyperfibrinogenemia has been demonstrated in colorectal [11], cervical, oesophageal [12], and pancreatic cancers [13]. In NSCLC, hyperfibrinogenemia is associated with T-stage disease and tumour volume [14]. However, the usefulness of plasma fibrinogen concentrations in evaluating patients with resectable/non-resectable tumours, as well as in predicting the survival of NSCLC patients, is still under debate [15].

To address these issues, we performed a prospective investigation to examine the relationships between serum CRP and plasma fibrinogen levels and tumour size in patients with NSCLC and determined the prognostic importance of these biomarkers in survival following successful tumour resection.

\section{METHODS}

\section{Patients}

This prospective study was conducted with newly-diagnosed operable NSCLC patients enrolled between January 2006 and December 2010. NSCLC patients previously suffering or showing coexistence of any cancer apart from NSCLC, treated by radiotherapy or chemotherapy, or with other diseases suspected of influencing serum CRP or plasma fibrinogen concentrations were excluded. A total of 153 patients were enrolled at a tertiary hospital in China. The hospital's Institutional Review Board sanctioned all ethical permissions (Approval No. 2006/28020439) prior to inception of the study. Moreover, Council for International Organizations of Medical Sciences guidelines were adapted whilst dealing with human subjects [16]. Written consent was obtained from all participants.

The patients were thoroughly evaluated prior to surgery based on their demographics, detailed pathological history, physical observations, and general laboratory testing. Lung cancer staging was performed according to TNM classifications based on the revised staging system of the International Association for the Study of Lung Cancer (IASLC) by evaluating chest X-ray and CT scans. The maximum tumour diameter was also estimated and recorded [17].

An accurate evaluation of distant metastases was performed with bone scintigraphy, brain $\mathrm{MRI}$, and an abdominal CT scan. In patients suspected of having N2-N3 disease, cervical mediastinoscopy was performed. The final histologic diagnosis of each case was based on the stratification for lung cancer established by the WHO and IASLC [18].

Surgery was performed on all study patients, and, depending on the location and size of the tumour, lobectomy, bilobectomy, segmentectomy, or pneumonectomy was performed. Post-surgery, some patients received adjuvant chemotherapy, adjuvant radiotherapy, or radiochemotherapy when indicated. A standardised follow-up visit was conducted every 3 months for 2 years, then every 6 months for the third year and annually thereafter. During each follow-up visit, a detailed physical observation, full blood count, chest CT, brain MRI, and abdominal ultrasound were performed.

Patients received follow-up care from 1 to 48 months with a median of 23 months. During the follow-up period, some of the patients relapsed, had a distant metastasis (or both), and/or died. Progression-free survival (PFS) was calculated as the time from surgery to local or distant tumour progression. Overall survival (OS) was calculated as the time from surgery until the time of death or final follow-up. 


\section{Serum CRP and fibrinogen measurements}

Blood samples from histologically confirmed NSCLC patients were collected by peripheral venous puncture. For serum CRP analysis, blood samples were collected in serum separator tubes and centrifuged at $1000 \times \mathrm{g}$ for $10 \mathrm{~min}$ at $4{ }^{\circ} \mathrm{C}$. CRP levels were measured by routine clinical laboratory test protocols using an automatic nephelometer according to the manufacturer's instructions (Beckman Coulter Inc., Fullerton, CA, USA). Plasma samples for fibrinogen analysis were separated by centrifuging blood samples collected in EDTA tubes at $1500 \times g$ for $15 \mathrm{~min}$ at $4^{\circ} \mathrm{C}$. Fibrinogen levels were measured using a clotting assay on an automated blood coagulation analyser (CA-7000; Sysmex Corp., Kobe, Japan) with thrombin reagent. All plasma and serum samples were stored at $-80{ }^{\circ} \mathrm{C}$ in Eppendorf tubes prior to analysis and were analysed on the same day. A plasma fibrinogen concentration $<4.0 \mathrm{~g} / \mathrm{L}$ was considered normal and a concentration $\geq 4.0 \mathrm{~g} / \mathrm{L}$ was considered as hyperfibrinogenemic. A normal serum CRP level was defined as $\leq 0.8 \mathrm{mg} / \mathrm{dL}$ according to the manufacturer's manual. However, on the basis of clinical relevance [17], a second cut-off value of $>20 \mathrm{mg} / \mathrm{L}$ was considered elevated.

\section{Statistical analysis}

Statistical calculations were performed using SPSS (version 17.0; SPSS Inc., Chicago, IL, USA). Categorical variables were summarised as proportions and compared using the chi-squared test. The relationships between the average serum CRP and plasma fibrinogen levels and clinicopathological variables were compared using the Kruskal-Wallis test, whilst Spearman's rank correlation coefficient was employed to assess the correlation between maximum tumour diameter and plasma fibrinogen and serum CRP concentrations. PFS and OS were determined by a Cox proportional hazards regression analysis. $P<0.05$ was considered statistically significant.

\section{RESULTS}

\section{Patient characteristics}

The present investigation enrolled 153 patients who were suffering from NSCLC. The demographic and clinical characteristic features of the patients involved are shown in Table 1. The patients had a median age of 61 years, ranging from 35 to 81 years; 109 (71\%) were male and $44(29 \%)$ were female. On the basis of WHO/IASLC stratification criteria for lung cancers, 78 tumours $(51 \%)$ were histologically diagnosed as adenocarcinoma, $68(44 \%)$ as squamous cell carcinoma, 5 (3.3\%) as large cell carcinoma, and $2(1.3 \%)$ as other. A total of 92 patients were smokers (ever/current) $(60.1 \%)$. Clinical staging performed according to the new IASLC criteria revealed that $64(42 \%)$ patients had stage I, 41 (27\%) had stage II, 42 (27.5\%) had stage III, and $6(3.9 \%)$ had stage IV tumours. Overall, $112(72 \%)$ patients underwent a lobectomy whilst the others underwent bilobectomy, segmentectomy, or pneumonectomy (Table 1).

Table 1: Demographic and clinical characteristics of the patients $(N=153)$

\begin{tabular}{lc}
\hline Variable & Patients, $\mathbf{N}(\%)$ \\
\hline Sex & $109(71.2)$ \\
Male & $44(28.8)$ \\
Female & \\
Age (years) & $104(68.0)$ \\
$<65$ & $49(32.0)$ \\
$\geq 65$ & \\
Smoking & \\
Smoker & $92(60.1)$ \\
Non-smoker & $61(39.9)$ \\
& \\
Histological type & \\
Squamous cell & $68(44.4)$ \\
carcinoma & \\
Adenocarcinoma & $78(51.0)$ \\
Large cell carcinoma & $5(3.3)$ \\
Other & $2(1.3)$ \\
Pathologic tumour & \\
factor & \\
$\mathrm{T}_{1}$ & \\
$\mathrm{~T}_{2}$ & \\
$\mathrm{~T}_{3}$ & $14(9.2)$ \\
$\mathrm{T}_{4}$ & $113(73.8)$ \\
Pathologic lymph node & $15(9.8)$ \\
factor & $11(7.2)$ \\
$\mathrm{N}_{0}$ & \\
$\mathrm{~N}_{1}$ & \\
$\mathrm{~N}_{2}$ & \\
Clinical stage & \\
I II & \\
III & \\
IV & \\
Type of resection & $25(2.9)$ \\
Pneumonectomy & \\
Bilobectomy & \\
Lobectomy & \\
Segmentectomy & \\
\hline
\end{tabular}




\section{Serum CRP and plasma fibrinogen concentrations}

We observed a median serum CRP concentration amongst all patients of approximately $4.86 \mathrm{mg} / \mathrm{L}$ (range: $0.67-128.46$ $\mathrm{mg} / \mathrm{L}$ ) and a median plasma fibrinogen level of $3.53 \mathrm{~g} / \mathrm{L}$ (range: 1.64-9.67 g/L). These two biomarkers were markedly correlated with sex, smoking status, histological type, tumour stage, and clinical stage. Higher levels of serum CRP and plasma fibrinogen were correlated with squamous cell carcinoma ( $p \leq 0.001$ and 0.001 , respectively) compared to non-squamous cell carcinoma, and with pathological tumour stage ( $p$ $=0.001$ and $<0.001$, respectively) (Table 2). Spearman's correlation coefficient established a positive correlation between maximum pathological tumour diameter and serum CRP level $(r=0.471, p<0.001)$ (Fig. 1). The scatter plot in Fig. 2 also reveals that plasma fibrinogen concentration and maximum pathologic tumour volume were positively associated $(r=0.381, p=$ 0.002). Moreover, the serum concentrations of both biomarkers (CRP and fibrinogen) were positively associated with each other $(r=0.410$, $p<0.001)$. Overall, $62 \%(95 / 153)$ of the patients had an elevated serum fibrinogen ( $>4 \mathrm{~g} / \mathrm{L}$ ) level compared to $38 \%(58 / 153)$ with a normal level. Additionally, approximately $63 \% \quad(97 / 153)$ of patients had an increased serum CRP ( $>20$ $\mathrm{mg} / \mathrm{L})$ level compared to $37 \%$ (56/153) with a normal level.

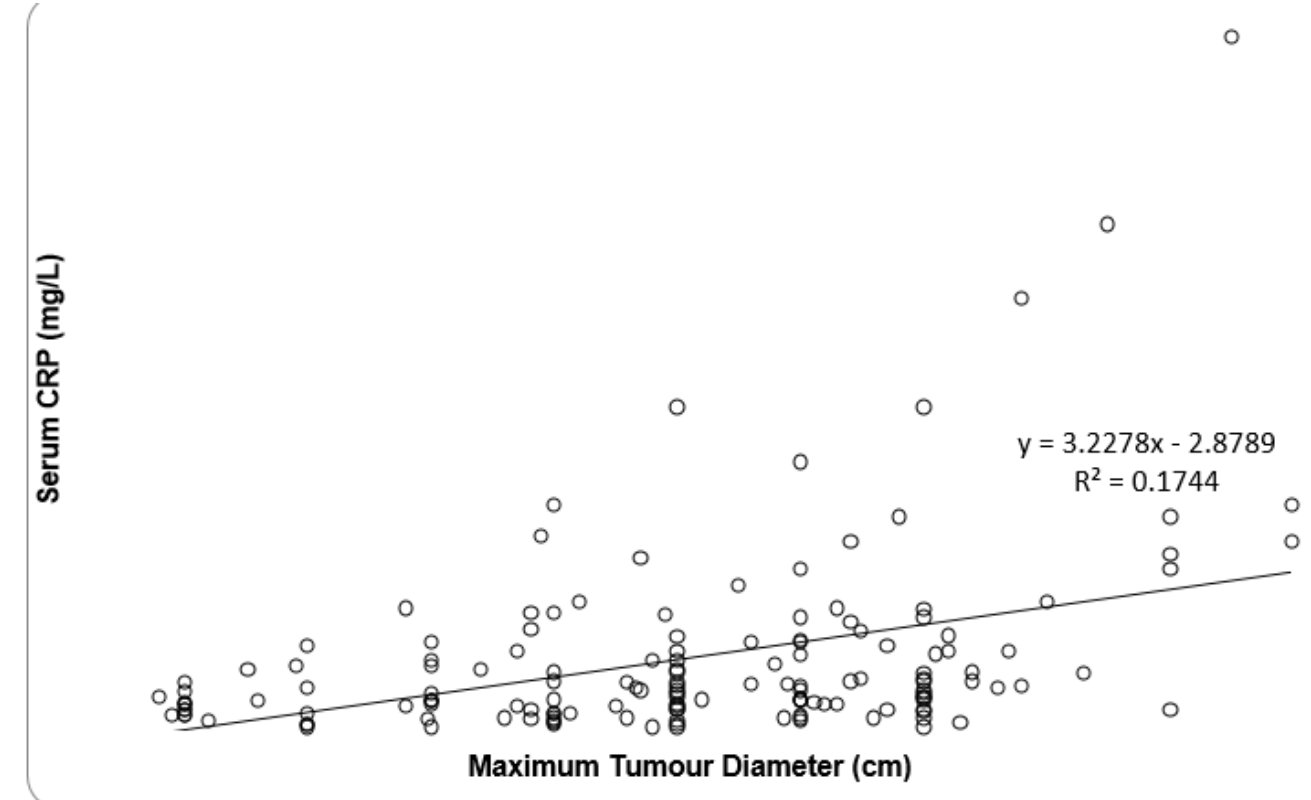

Figure 1: Scatter plot showing the correlation between serum CRP level and maximum tumour size

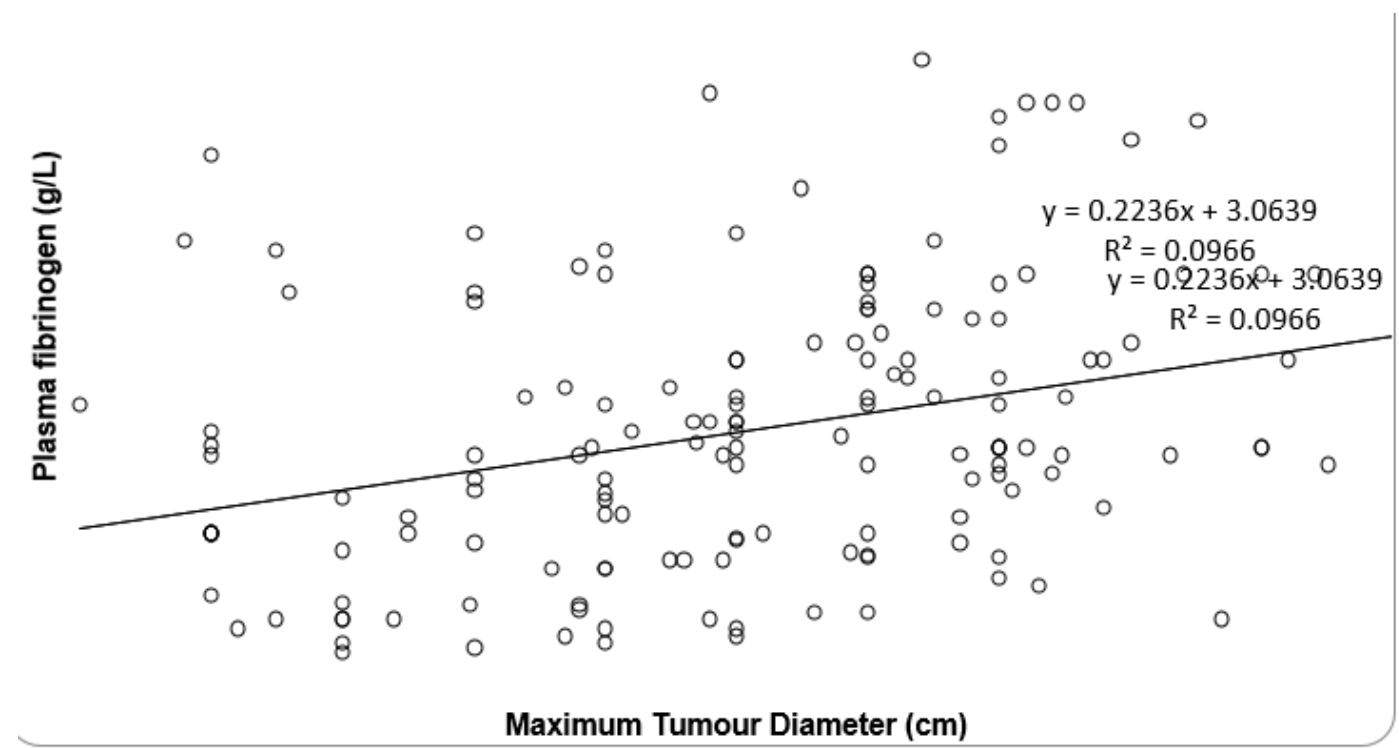

Figure 2: Scatter plot showing the correlation between plasma fibrinogen level and maximum tumour size 
Table 2: Serum C-reactive protein (CRP) and plasma fibrinogen levels according to clinicopathological parameters in patients with non-small cell lung cancer

\begin{tabular}{|c|c|c|c|c|}
\hline \multirow[t]{2}{*}{ Factor } & \multicolumn{2}{|c|}{ Serum CRP (mg/L) } & \multicolumn{2}{|c|}{ Plasma fibrinogen (g/L) } \\
\hline & Median & $p$ & Median & $p$ \\
\hline Sex & & 0.001 & & $<0.001$ \\
\hline Male & 5.06 & & 3.72 & \\
\hline Female & 4.81 & & 3.39 & \\
\hline Age (years) & & 0.39 & & 0.46 \\
\hline$<65$ & 4.77 & & 3.42 & \\
\hline$\geq 65$ & 4.98 & & 3.81 & \\
\hline Smoking & & 0.001 & & 0.002 \\
\hline Smoker & 4.79 & & 3.71 & \\
\hline Non-smoker & 4.62 & & 3.29 & \\
\hline Histology & & $<0.001$ & & 0.001 \\
\hline Squamous cell carcinoma & 5.04 & & 3.97 & \\
\hline Adenocarcinoma & 4.48 & & 3.25 & \\
\hline Large cell carcinoma & 4.37 & & 3.28 & \\
\hline Other & 4.77 & & 3.41 & \\
\hline Tumour factor & & 0.001 & & $<0.001$ \\
\hline $\mathrm{T}_{1}$ & 4.40 & & 3.08 & \\
\hline $\mathrm{T}_{2}$ & 4.82 & & 3.47 & \\
\hline$T_{3}$ & 5.73 & & 4.49 & \\
\hline $\mathrm{T}_{4}$ & 5.02 & & 3.77 & \\
\hline Lymph node factor & & 0.093 & & 0.061 \\
\hline $\mathrm{N}_{0}$ & 4.76 & & 3.41 & \\
\hline $\mathrm{N}_{1}$ & 4.97 & & 3.67 & \\
\hline $\mathrm{N}_{2}$ & $4-89$ & & 3.59 & \\
\hline Clinical stage & & $<0.001$ & & 0.001 \\
\hline 1 & 4.78 & & 3.45 & \\
\hline II & 4.96 & & 3.64 & \\
\hline III & 4.85 & & 3.70 & \\
\hline IV & 4.98 & & 3.75 & \\
\hline
\end{tabular}

Tumour resection and levels of serum CRP and fibrinogen

Incomplete tumour resection occurred in $28 \%$ (27/95) of patients with an elevated plasma fibrinogen level (> $4 \mathrm{~g} / \mathrm{L}$ ) compared to only $10 \%$ $(6 / 58)$ with a normal fibrinogen $(\leq 4 \mathrm{~g} / \mathrm{L})$ level $(p$ $=0.008)$, and in $30 \%(29 / 97)$ of patients with a serum CRP > $20 \mathrm{mg} / \mathrm{L}$ compared to only $11 \%$ (6/56) with a CRP level $\leq 20 \mathrm{mg} / \mathrm{L}(p=0.006)$. This combined analysis indicates that when either the plasma fibrinogen level was $\leq 4 \mathrm{~g} / \mathrm{L}$ or the CRP level was $\leq 20 \mathrm{mg} / \mathrm{L}$, only $10 \%(10 / 99)$ of patients had an incomplete resection, which is quite low compared to $28 \%(15 / 54)$ of patients with a plasma fibrinogen level $>4 \mathrm{~g} / \mathrm{L}$ and a serum CRP level > $20 \mathrm{mg} / \mathrm{L}(p=0.005)$.

\section{Correlations between serum CRP and fibrinogen levels and survival}

The estimated 3-year PFS and OS rates were 60 and $79 \%$, respectively. These survival rates were inversely proportional to the plasma fibrinogen and serum CRP concentrations. Compared to patients with a normal serum fibrinogen level, patients with hyperfibrinogenemia exhibited lower 3-year PFS (42.8 vs. $73.6 \%$ ) and OS (56.0 vs. $80.9 \%$ ) rates. Similarly, compared to patients with a normal serum CRP level, patients with an elevated serum CRP level had lower 3-year PFS (46.2 vs. $71.2 \%)$ and OS (52.0 vs. $76.4 \%)$ rates.

A significantly higher survival rate was observed in patients with a stage I or II tumour who had a serum CRP level $\leq 20 \mathrm{mg} / \mathrm{L}$ and a plasma fibrinogen level $\leq 4 \mathrm{~g} / \mathrm{L}$ compared to those with CRP and fibrinogen values higher than the abovementioned values $(p<0.001)$. A univariate analysis revealed that post-resection, OS was significantly related to age, clinical $\mathrm{T}$ and $\mathrm{N}$ category, cancer stage, and the type of resection procedure (Table 3 ). Cox proportional hazards regression analysis revealed that plasma 
Table 3: Relationships between patient characteristics and post-operative overall survival

\begin{tabular}{lccc}
\hline Variable & & $\begin{array}{c}\text { Median duration } \\
\text { (months) }\end{array}$ & $\boldsymbol{p}$ \\
\hline Sex & Male:Female & $29: 28$ & 0.214 \\
Age (years) & $\leq 65: \geq 66$ & $32: 26$ & 0.031 \\
Smoking & Smokers:Non-smokers & $28: 27$ & 0.189 \\
Stage & I:Il:III:IV & $34: 30: 26: 18$ & $<0.001$ \\
Tumour factor & T1:T2:T3 & $33: 28: 21$ & 0.032 \\
Histology* & Squamous:Non-squamous & $28: 27$ & 0.284 \\
Lymph node factor & N0:N1, N2 & $34: 31: 25$ & $<0.001$ \\
Resection & Lobectomy, bilobectomy:Pneumonectomy & $30: 23: 16$ & $<0.001$ \\
\hline "Squamous cell carcinoma:Non-squamous cell carcinoma (adenocarcinoma, large cell carcinoma, \\
and other)
\end{tabular}

Table 4: Associations between serum C-reactive protein (CRP) and plasma fibrinogen levels and patient survival ${ }^{\#}$

\begin{tabular}{|c|c|c|c|c|c|c|}
\hline Patient survival & Crude HR & $95 \% \mathrm{Cl}$ & $p$ & Adjusted HR & $95 \% \mathrm{Cl}$ & $p$ \\
\hline \multicolumn{7}{|l|}{ Progression-free survival } \\
\hline $\begin{array}{l}\text { Serum CRP concentration }(<20 \mathrm{mg} / \mathrm{L}) \\
\text { Serum CRP concentration }(>20 \mathrm{mg} / \mathrm{L})\end{array}$ & $\begin{array}{c}1 \\
1.53\end{array}$ & $1.1-2.1$ & 0.004 & $\begin{array}{c}1 \\
1.31\end{array}$ & $1.05-2.2$ & 0.01 \\
\hline Plasma fibrinogen concentration $(<4 \mathrm{~g} / \mathrm{L})$ & 1.00 & & & $\begin{array}{l}1.01 \\
1\end{array}$ & $1.00-2.2$ & 0.01 \\
\hline Plasma fibrinogen concentration (> $4 \mathrm{~g} / \mathrm{L}$ ) & 1.49 & $1.1-2.2$ & 0.005 & 1.44 & $1.09-2.13$ & 0.004 \\
\hline \multicolumn{7}{|l|}{ Overall survival } \\
\hline Serum CRP concentr & 1 & & & 1 & & \\
\hline Serum CRP concentration (> $20 \mathrm{mg} / \mathrm{L}$ ) & 2.06 & $1.3-3.1$ & 0.001 & 1.72 & $1.20-2.66$ & 0.005 \\
\hline Plasma fibrinogen concentration $(<4 \mathrm{~g} / \mathrm{L})$ & 1 & & & 1 & & \\
\hline Plasma fibrinogen concentration $(>4 \mathrm{~g} / \mathrm{L})$ & 2.12 & $1.5-3.2$ & 0.002 & 1.65 & $1.38-3.62$ & 0.017 \\
\hline
\end{tabular}

${ }^{\#}$ Association determined by Cox proportional hazards regression; adjusted for age, sex, smoking status, stage, grade, and histological type. "Hazard ratio $(H R)$ calculated with respect to normal biomarker levels. A p-value < 0.05 was considered statistically significant. $\mathrm{Cl}$, confidence interval

fibrinogen and serum CRP concentrations were reliable prognostic markers in NSCLC.

In patients with hyperfibrinogenemia, the hazard ratio (HR) was 1.44 (95\% confidence interval $[\mathrm{Cl}]:$ 1.09-2.13) for disease progression and 1.65 (95\% Cl: 1.38-3.62) for death. Additionally, for patients with an elevated serum CRP level $(>20$ $\mathrm{mg} / \mathrm{L})$, the HR was $1.31(95 \% \mathrm{Cl}: 1.05-2.2)$ for disease progression and $1.72(95 \% \mathrm{Cl}: 1.20$ 2.66) for death (Table 4).

\section{DISCUSSION}

In our current investigation, elevated serum CRP and fibrinogen concentrations were positively associated with increased tumour diameter, sex, smoking status, histological type, pathologic tumour classification, and clinical stage. Patients with elevated serum CRP and fibrinogen concentrations were more likely to have incomplete tumour resection. In addition, elevated serum CRP and fibrinogen levels were determined to be independent predictors of worse patient outcomes. Thus, this study demonstrates an association between NSCLC, coagulation status, and physiological inflammation that suggests clinical benefits for selecting patients with NSCLC for surgery as well as their post-operative prognostic implications.

The serum CRP level increases in several acute and chronic inflammatory disease conditions, including malignancy. The mechanism of the elevated serum CRP level in cancer patients is reportedly due to the production of proinflammatory cytokines (i.e., IL-1, IL-2, TNF- $\alpha$, and IFN- $\gamma$ ) involved in carcinogenesis $[7,1919]$. In the present investigation, sex, smoking, histological type, cancer stage classification, and clinical stage were all positively correlated with a higher serum CRP concentration, and Spearman's correlation showed a strong positive association between maximum pathological cancer dimension and serum CRP level. These observations are consistent with previous studies of NSCLC and other malignancies, and they suggest that a greater cancer cell burden is more likely to augment the production of inflammatory cytokines and therefore higher serum levels of CRP [19].

With the enhanced proliferation of tumour cells and their interactions with the stroma and other 
supportive tissues that mediate tumour growth, there is increased expression of fibrinolytic and procoagulant factors that are generally lacking in normal stroma cells [20]. Furthermore, substantial amounts of fibrin and fibrinogen are deposited around solid tumours, implying that fibrinogen induces the development of the tumour stroma $[14,20]$. Additionally, fibrinogenmediated cellular interactions play a role in cell proliferation, cell migration, apoptosis, inflammatory factor production, and angiogenesis $[14,20,21]$. Moreover, the development of a platelet-fibrin-tumour cell promotes endothelial adhesion, as well as increased attachment; therefore, fibrinogen forms a layer on the surface of cancer cells to aid in the attachment of growth factors and induce tumour cell dispersion and metastasis [22]. Moreover, the fibrinogen coating may result in the protection of cancer cells from immune surveillance and extend malignant cell survival [21,22]. These observations are important provided the findings of this study and other investigations that showed a positive correlation between fibrinogen concentration with pathological tumour phase and primary tumour diameter but not with the pathological $\mathrm{N}$ stage [14].

In this study, the rate of partial/incomplete resection was higher in patients with elevated serum CRP and plasma fibrinogen levels, demonstrating a relationship between these biomarkers and tumour malignancy. This may be useful for screening patients who can benefit from surgery. Furthermore, it may aid in identifying subpopulations of NSCLC patients who require a detailed evaluation for preoperative chemotherapy to reduce tumour size. Unlike this study, a previous study did not demonstrate significant findings between incomplete resection with serum CRP, plasma fibrinogen, or both biomarkers, although a trend towards a higher rate of incomplete resection was observed with increasing levels of these biomarkers. The major difference in these findings is that the previous study used higher cut-off levels for fibrinogen (> $5 \mathrm{~g} / \mathrm{L}$ ) and CRP (> $40 \mathrm{mg} / \mathrm{L}$ ) to demonstrate increased levels of these biomarkers relative to the current study [14].

Plasma fibrinogen and serum CRP concentrations were markedly correlated with patient outcomes. Multivariate calculations determined by the Cox proportional hazards model demonstrated that increased concentrations of CRP and fibrinogen were independent predictors of poor OS and PFS. The present study also suggests a stage-dependent relationship between these pre-operative biomarkers and survival. Our results are consistent with those from earlier investigations and a systematic review that revealed increased serum CRP concentration as a poor prognostic indicator in patients with NSCLC [13-15]. In addition, our findings agree with recent studies indicating plasma fibrinogen level as a new reliable prognostic indicator for PFS and OS in NSCLC $[18,19,22]$.

\section{Limitations of the study}

Although the present study contributes significantly to our knowledge of NSCLC biomarkers, it has its own limitations, including a limited sample size. It was also conducted only at a tertiary care hospital.

\section{CONCLUSION}

Serum CRP and plasma fibrinogen concentrations were elevated in patients with NSCLC and correlated with tumour size. Preoperative levels of serum CRP and plasma fibrinogen may serve as additional indicators of tumour resectability, wherein a high tumour resection rate is possible in patients with favourable pre-operative levels of these biomarkers. Elevated levels of these biomarkers in the pre-operative period are poor prognostic factors of OS and PFS in NSCLC patients.

\section{DECLARATIONS}

\section{Acknowledgement}

The authors acknowledge Xinhua Hospital, Shanghai Jiaotong University of Medicine College, and Changhai Hospital for their support for the present study.

\section{Conflict of Interest}

No conflict of interest associated with this work.

\section{Contribution of Authors}

The authors declare that this work was done by the authors named in this article and all liabilities pertaining to claims relating to the content of this article will be borne by them.

\section{Open Access}

This is an Open Access article that uses a funding model which does not charge readers or their institutions for access and distributed under the terms of the Creative Commons Attribution License (http://creativecommons.org/licenses/by 
14.0) and the Budapest Open Access Initiative (http://www.budapestopenaccessinitiative.org/rea d), which permit unrestricted use, distribution, and reproduction in any medium, provided the original work is properly credited.

\section{REFERENCES}

1. Stewart BW, Wild CP. World Cancer Report 2014. Lyon, France: International Agency for Research on Cancer. 2014

2. American Cancer Society. Cancer Facts \& Figures 2004. Available at: http://www.cancer.org/downloads/STT/CAFF2005f4PW Secured.pdf. Accessed March 9, 2015.

3. Horita N, Woo T, Miyazawa N, Kaneko T. Pre-operative chemotherapy for non-small cell lung carcinoma. Transl Lung Cancer Res 2015; 4: 5-7

4. Detterbeck FC, Mazzone PJ, Naidich DP, Bach PB. Screening for Lung Cancer: Diagnosis and Management of Lung Cancer, 3rd edn: American College of Chest Physicians Evidence-Based Clinical Practice Guidelines. Chest 143(5 Suppl): e78S-92S.

5. National Comprehensive Cancer Network. NCCN Clinical Practice Guidelines in Oncology. Lung Cancer Screening, $\quad v \quad$ 2.2014. Available at http://www.nccn.org/professionals/physician_gls/pdf/lun g_screening.pdf. Accessed Feb. 28, 2015.

6. McMillan DC, Elahi MM, Sattar N, Angerson WJ, Johnstone J, McArdle CS. Measurement of the systemic inflammatory response predicts cancer-specific and non-cancer survival in patients with cancer. Nutr Cancer 2001; 41: 64-69.

7. Heikkilä K, Ebrahim S, Lawlor DA. A systematic review of the association between circulating concentrations of $C$ reactive protein and cancer. J Epidemiol Community Health 2007; 61: 824-833.

8. Koch A, Fohlin H, Sorenson S. Prognostic significance of $C$-reactive protein and smoking in patients with advanced non-small cell lung cancer treated with firstline palliative chemotherapy. J Thorac Oncol 2009; 4: 326-332.

9. O'Dowd C, McRae LA, McMillan DC, Kirk A, Milroy $R$. Elevated preoperative $C$-reactive protein predicts poor cancer specific survival in patients undergoing resection for non-small cell lung cancer. J ThoracOncol 2010; 5: 988-992

10. Jin $Y$, Sun $Y$, Shi $X$, Zhao J, Shi L, Yu X. Prognostic value of circulating $C$-reactive protein levels in patients with non-small cell lung cancer: a systematic review with meta-analysis. Cancer Res Ther 2014;10 Suppl: C160C166

11. Yamashita H, Kitayama J, Taguri M, Nagawa H. Effect of preoperative hyperfibrinogenemia on recurrence of colorectal cancer without a systemic inflammatory response. World J Surg 2009; 33: 1298-305.

12. Takeuchi $H$, Ikeuchi S, Kitagawa $Y$, Shimada A, Oishi $T$, Isobe $Y$, Kubochi $K$, Kitajima $M$, Matsumoto $S$. Pretreatment plasma fibrinogen level correlates with tumor progression and metastasis in patients with squamous cell carcinoma of the esophagus. J Gastroenterol Hepatol 2007; 22: 2222-2227.

13. Guo Q, Zhang B, Dong X, Xie Q, Guo E, Huang $H, W u$ $Y$.. Elevated levels of plasma fibrinogen in patients with pancreatic cancer: possible role of a distant metastasis predictor. Pancreas 2009; 38: e75-e79.

14. Zhao J, Zhao $M$, Jin B, Yu P, Hu X, Teng $Y$, Zhang J, Luo $Y$, Zhang $L$, Zheng $S$, et al. Tumor response and survival in patients with advanced nonsmall-cell lung cancer: the predictive value of chemotherapy-induced changes in fibrinogen. BMC Cancer 2012; 12: 330.

15. Sheng $L$, Luo M, Sun $X$, Lin N, Mao W, Su D. Serum fibrinogen is an independent prognostic factor in operable non-small cell lung cancer. Int J Cancer. 2013; 133: $2720-2725$.

16. International ethical guidelines for biomedical research involving human subjects. Geneva: Council for International Organization of Medical Sciences; 1993. Council for International Organizations of Medical Sciences.

17. Vallies E, Shepherd FA, Crowley J, Van Houtte $P$, Postmus PE, Carney D, et al.; International Association for the Study of Lung Cancer International Staging Committee and Participating Institutions. The IASLC Lung Cancer Staging Project: proposals regarding the relevance of TNM in the pathologic staging of small cell lung cancer in the forthcoming (seventh) edition of the TNM classification for lung cancer. J Thorac Oncol 2009; 4: 1049-1059. 